\title{
“UNSTEADINESS IN LIFE PREDICTS DOOM" - DANDY WALKER VARIANT PRESENTING AS LATE ONSET ATAXIA IN AN ADOLESCENT MALE - A CASE REPORT.
}

Shivkumar Gopalakrishnan¹, Sangeetha Kandasamy², Antony Raj James S³

\section{HOW TO CITE THIS ARTICLE:}

Shivkumar Gopalakrishnan, Sangeetha Kandasamy, Antony Raj James S. "Unsteadiness in Life Predicts Doom Dandy Walker Variant presenting as Late Onset Ataxia in an Adolescent Male - A Case Report". Journal of Evolution of Medical and Dental Sciences 2014; Vol. 3, Issue 03, January 20; Page: 623-626,

DOI: $10.14260 /$ jemds/2014/1876

INTRODUCTION: The Dandy-Walker malformation was first described in 1887 by Sutton and was further characterized by Dandy and Blackfan in 1914 and Taggart and Walker in 1942 1,2. True Dandy-Walker malformation [DWM]consists of cerebellar vermis hypoplasia, posterior fossa enlargement with elevation of the torcula and an enlarged 4th ventricle extending posteriorly as a retrocerebellar cyst. Other malformations with less severe cerebellar vermis hypoplasia and generally smaller posterior fossa fluid collections were categorized as "Dandy-Walker variants". We herein report a case of Dandy Walker Variant who presented in an unusual manner.

CASE REPORT: Our patient, a 17 yrs. old adolescent male presented to the hospital with intractable vomit and unsteadiness $\mathrm{x} 3$ days. On detailed elicitation of history, he was apparently asymptomatic till 3 days ago. There was no significant precipitating factor like fever, drug intake or trauma. He is not gainfully employed due to "lack of interest". He had been a poor performer at school and dropped out at $8^{\text {th }}$ Std. Patient is $3^{\text {rd }}$ born of consanguineous parents and has 2 elder siblings. Sister is mentally retarded and requires support for ADL; brother has normal mentation and physique.

On Clinical Examination, patient was dehydrated, confined to bed, anthropometry was within normal limits. On detailed Neurological Examination, he had an average IQ 80-90, MMSE - >18 and speech was staccato. He had evidence of cerebellar dysfunction like truncal ataxia, dysmetria, dyssynergia and nystagmus. Other parts of CNS examination were unremarkable.

Laboratory Workup of Patient revealed normal blood counts and basic biochemical analysis. Patient had hyponatremia [Na+122MEq/L]. ECG revealed sinus bradycardia. CT scan brain revealed cerebellar vermis atrophy with posterior fossa cyst/ supra tentorial structures normal -features s/o Dandy Walker Variant. MRI Brain was s/o partial vermis aplasia, no displacement, posterior fossa cyst - Dandy Walker Variant. ECHO Cardiography was normal study. Karyotype analysis was carried out which showed normal male karyotype, trisomies ruled out.

Since the patient's sister was also a retard we considered an inherited disorder and worked up the sibling sister. However, her laboratory tests, CR and MR imaging, Echocardiography and Karyotype analysis were all normal.

Course in the Hospital: Patient was managed conservatively with intravenous fluids, labyrinthine stimulants. His general condition improved, electrolytes reverted to normal and he was able to resume normal activities in 2 days. His sinus bradycardia persisted though for unknown reasons. He got discharged from the hospital on day 7. 
DISCUSSION: The number and complexity of recognized malformations of the brainstem and cerebellum have perplexed many neurologists over the last century. These disorders were recently extensively reviewed and classified ${ }^{3}$. As classically defined, "true" DWM consists of cerebellar vermis hypoplasia with upward vermis rotation and often elevation of the torcula, an enlarged 4th ventricle which extends posteriorly as a retrocerebellar cyst and hydrocephalus. There are 2 other related malformations which share the same continuum of developmental changes. The first group consists of malformations with less severe cerebellar vermis hypoplasia, less notable or absent upward rotation of the vermis and generally smaller posterior fossa fluid collections, categorized as "Dandy-Walker variants [DWV]." The second group consists of patients with large posterior fossa fluid collections, but with entirely normal size of the cerebellar vermis and hemispheres, termed "mega-cisterna magna"4.

Associated anomalies outside the central nervous system in association with DWS include cardiac defects, craniofacial abnormalities, gastrointestinal abnormalities, genitourinary abnormalities, respiratory aberrations and musculoskeletal dysmorphisms 5 .

Parisi and Dobyns in their publication coined a new term for DWV and classified this entity as Cerebellar Vermian Hypoplastic Disorders [CVH] ${ }^{6}$. DWV occurs as a sporadic disorder although controversy looms large on a probable inheritance pattern. There have been reports of an X-linked inherited pattern of DWV7. Recently, mutations of the oligophrenin-1 gene (OPHN1) at Xq12, previously associated with X-linked mental retardation, have been identified in many patients 8.Other possible genetic defects include Trisomy 22 chromosome (Searson et al), 13q deletion (Radjan F et al), Trisomies 18 (Hau Y J et al) and 6p terminal deletion (Chen KM et al). In our case, the Karyotype of both the siblings was essentially normal.

Clinical Features: Although there is no direct estimate of isolated DWS incidence, DWM has an estimated incidence of $1 / 2500$ to $1 / 3500$ births ${ }^{9}$. Infants with "true" DWM often present in the neonatal period with macrocephaly, hydrocephalus, developmental delay, apneic episodes and seizures, etc ${ }^{10}$. Despite the magnitude of cerebellar and posterior fossa malformation, the presence of mental retardation, motor deficits and cerebellar dysfunction is highly variable among such patients ${ }^{11}$. Ataxia and nystagmus are seen in many, but cerebellar signs are variable and may not be present. There are reports of DWM diagnosed incidentally after cranial imaging studies performed for other indications ${ }^{12}$.

Reports published earlier reveal that Dandy Walker Variants can present in adulthood with neuropsychiatric manifestations like acute psychosis, progressive cognitive decline and behavioral disorders 13, 14.There have been previous reports of consecutive involvement of 2 siblings with prototype features ${ }^{14}$ which is likely an inherited defect. Such adulthood presentations are known to occur with trisomy $22^{13}$. However, to the best of our knowledge, this is the only case reported so far which has an asymptomatic adolescent DWV male and a mentally retarded sibling female with normal brain imaging. This leaves an as yet identified genetic defect causing this manifestation.

Management: The management is largely supportive. Controversy looms large over the optimal management strategy for DWM. Treatment by either direct shunting of the lateral ventricles, shunting of the posterior fossa cyst, or both, to relieve symptomatic hydrocephalus has met with mixed success ${ }^{11}$.In general, shunting is best advocated for those with severe raised intracranial 
tension and resultant progressive neurologic decline DWV patients commonly don't have obstructive hydrocephalus and shunting is of doubtful value in improving outcome.

CONCLUSION: Dandy Walker Variants have been observed to present in childhood with varying degrees of cognitive, behavioral and motor defects. Controversy exists on an inheritance pattern as well. This is the first case report wherein the patient presented as an adolescent with acute onset ataxia. Furthermore, the patient's elder sister is mentally retarded, which hints towards a probable inheritance pattern. Gross chromosomal disorders like trisomy were ruled out by karyotyping.

One question yet unanswered is "Can a single gene defect manifest as DWV in one sibling and only mental retardation in another?" Only further genetic evaluation in the form of FISH or Microarray analysis could find the plausible answer to this question. This case is reported for its rarity and rarer mode of presentation.

ACKNOWLEDGEMENT: The authors acknowledge the valuable help and guidance of all staff of Dept. of Internal Medicine and Biochemistry, who aided in evaluating this patient.

\section{REFERENCES:}

1. W.E. Dandy, K.D. Blackfan. Internal hydrocephalus: an experimental, clinical, and pathological study, Am. J. Dis. Child. 8 (1914) 406-482.

2. J.K. Taggart, A.E. Walker. Congenital atresia of the foramens of Luschka and Magendie, Arch. Neurol. Psychiatry 48 (1942), 583-612

3. Barkovich, A.J., Millen, K.J., Dobyns W.B. A developmental and genetic classification for midbrain-hind brain malformations. Brain 2009; 132, 3199-3230.

4. S. Patel, A.J. Barkovich. Analysis and classification of cerebellar malformations, AJNR Am J Neuroradiol. 2002 Aug; 23(7):1074-87.

5. Sasaki-Adams D, Elbabaa SK, Jewells V, Carter L, Campbell JW, Ritter AM. The Dandy-Walker variant: a case series of 24 pediatric patients and evaluation of associated anomalies, incidence of hydrocephalus, and developmental outcomes. J Neurosurg Pediatr. 2008; 2:194-199. [PubMed: 18759601]

6. Melissa A. Parisia, William B. Dobyns. Human malformations of the midbrain and hindbrain: review and proposed classification scheme. Molecular Genetics and Metabolism 80 (2003) 3653.

7. E.L. Wakeling, M. Jolly, N.M. Fisk, C. Gannon, S.E. Holder. X-linked inheritance of Dandy-Walker variant, Clin. Dysmorphol. 11 (2002) 15-18.

8. N. Philip, B. Chabrol, A.M. Lossi, C. Cardoso, R. Guerrini, W.B. Dobyns, C. Raybaud, L. Villard. Mutations in the oligophrenin-1 gene (OPHN1) cause $X$ linked congenital cerebellar hypoplasia, J. Med. Genet. 40 (2003) 441-446.

9. Brain, HA. Human Malformations and Related Anomalies. Stevenson, R.; Hall, J.; Goodman, R., editors. Vol. 2. New York: Oxford University Press; 1993. p. 89-95.

10. J.-F. Hirsch, A. Pierre-Kahn, D. Renier, C. Sainte-Rose, E. Hoppe-Hirsch. The Dandy-Walker malformation: a review of 40 cases, J. Neurosurg. 61 (1984) 515-522.

11. P.C. Gerszten, A.L. Albright. Relationship between cerebellar appearance and function in children with Dandy-Walker syndrome, Pediatr. Neurosurg. 23 (1995) 86-92. 
12. H.L. Lipton, T.J. Preziosi, H. Moses. Adult onset of the Dandy- Walker syndrome, Arch. Neurol. 35 (1978) 672-674.

13. Searson R, Sridharan S. Neuropsychological and behavioural phenotype of Dandy Walker Variant presenting with chromosome 22 trisomy: a case study. J Intellect Disabil. 2013 Jun; 17(2):102-6.

14. Engelhard HH, Meyer JR. Adult onset presentation of Dandy Walker Variant in siblings. Surg Neurol. 1995 Jul; 44(1):43-7.

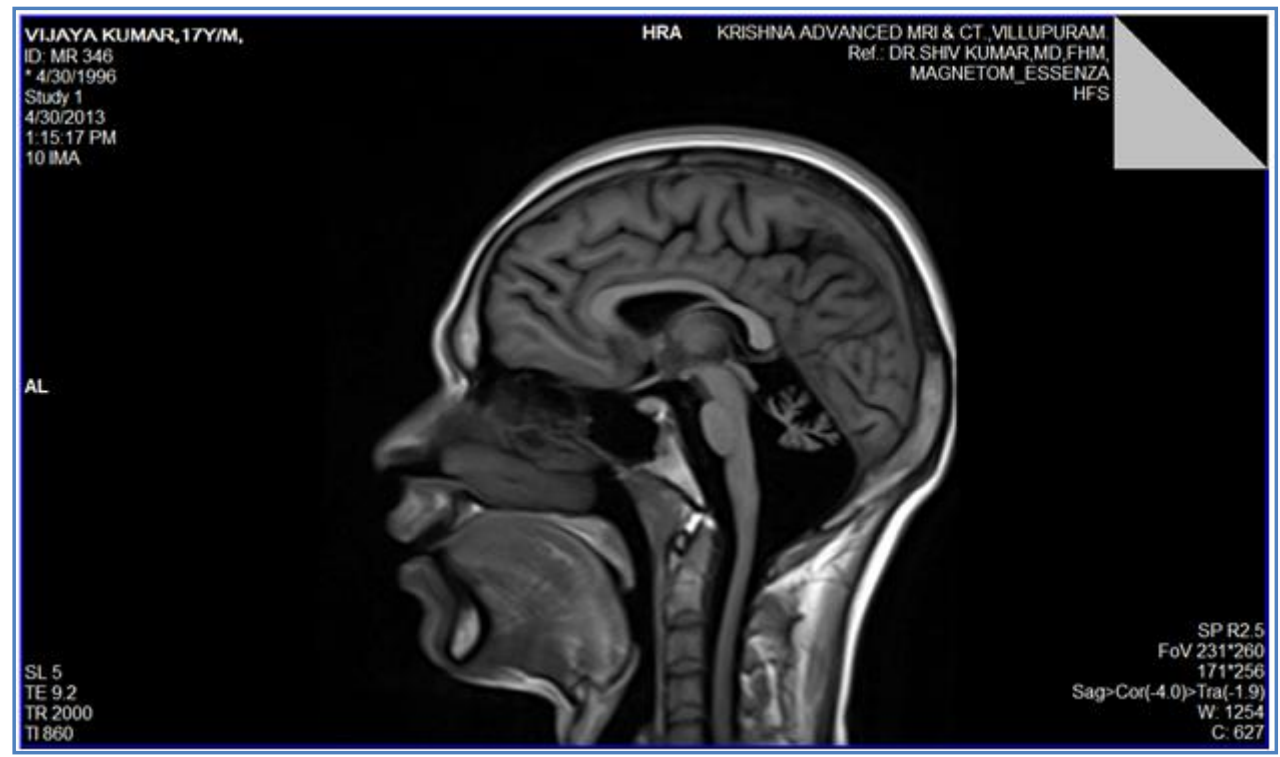

Image 1. Dandy Walker Variant showing partial vermian atrophy and posterior fossa cyst.

\section{AUTHORS:}

1. Shivkumar Gopalakrishnan

2. Sangeetha Kandasamy

3. Antony Raj James S

\section{PARTICULARS OF CONTRIBUTORS:}

1. Assistant Professor, Department of Internal Medicine, Government Villupuram Medical College and Hospital, Tamil Nadu.

2. Assistant Professor, Department of Biochemistry, Government Villupuram Medical College and Hospital, Tamil Nadu.

3. Trainee, Department of Medicine, Government Villupuram Medical College and Hospital, Tamil Nadu.

\section{NAME ADDRESS EMAIL ID OF THE CORRESPONDING AUTHOR:}

Dr. [Major] Shivkumar Gopalakrishnan, No. $8,4^{\text {th }}$ Cross Lane,

Pennayar Street, East Shanmugapuram Colony, Villupuram District, Tamil Nadu, India, PIN - 605602.

Email - gopalakrishnanshivkumar@gmail.com

Date of Submission: 25/12/2013.

Date of Peer Review: 26/12/2013.

Date of Acceptance: 06/01/2014.

Date of Publishing: 16/01/2014. 